\title{
Smart Waste Management System
}

\author{
P.V. Sai Suraj Yadav, L.Nagavardhan Reddy, M.Revathi
}

\begin{abstract}
In treating the waste bin to avoid overflow and get the environment polluted. The solution is with network of dustbins which takes the idea of IOT with Wireless Sensor Networks. We put forward the concept of smart garbage bins that is used to improve the dustbin techniques to avoid the pollution and health problems. The system is designed to send the data on level of the bin filling by collecting the data through wireless network. The system is on cycle technique in sending data continuously at the given time delayand the process takes less power so that the power consumption is low. Here we usedultrasonic sensors, moisture and mems sensors connected to the micro controller. By using the sensors we get the data how much the dustbin is filled and how much space is left these information is sent to the server so it is easy to know when it is filled so the precautions could be taken before it causing the pollution.
\end{abstract}

\section{INTRODUCTION}

\section{A. Problem Statements}

There are a few issues with the current existing framework that are being recognized. This will mirror the requirement for another effective framework for observing and deal with the refuse. The issues are recorded as beneath:Current rubbish checking framework is wasteful, time squander and required a tremendous measure of human vitality. It will make an unhygienic condition for encompassing condition and makes terrible stench which can prompt spread some fatal malady.

\section{B. Scope of the project}

Over the most recent few years, the utilization of IOT gadget has detonated, offering webcontrolled progressions for everything from wellbeing trackers to shrewd waste framework. The flooding of the waste canisters is basic in India. This will affect our general public, our environment. It will harm the natural qualities that lead to cause the contamination alongside the medical problems for human and different creatures too. We proposed an IOT based cost productive trash checking framework which will screen and alarm when the junk level crosses the limit dimension of the refuse canister. This procedure will be completed with the assistance of sensors and microcontroller. This will diminish the human endeavours, likewise lessens the fuel utilization of

Revised Manuscript Received on September 22, 2019.

P.V. Sai Suraj Yadav, Department of Computer Science and Engineering SRM Institute of Science and Technology,Kattankulathur.

L.Nagavardhan Reddy, Department of Computer Science and Engineering SRM Institute of Science and Technology,Kattankulathur.

M.Revathi, Department of Computer Science and Engineering SRM Institute of Science and Technology,Kattankulathur. transports offices. This task empowers the associations to address issues of brilliant waste administration framework. This framework enables the client to realize the fill dimension of every trash canister in a region or city at untouched, to give a savvy and efficient course to the truck drivers.

\section{Purpose of the project}

The diversion on proposed framework is to get mechanize the strong waste observing procedure and the board of the general gathering process utilizing IOT. To structure a methodical trash checking framework.

Moreover, the web administrations would likewise be utilized to disperse squander gathering plan, contact data of the waste authorities for various places in city. Framework can providegood step tosubjectsinterest in cleaning the waste for administration,furthermore will help on cross over to all barriers for people.

\section{LITERATURE SURVEY}

\section{A. Knowledge Transfer between Resource Management Agencies using automated network}

A calculated system for family unit squander the board in skyscraper private structures in Malaysia is proposed in this paper. This examination is supported dependent on: (1) the present circumstance of civil strong waste administration in Malaysia that (theoretically) has been influenced by inappropriate information exchange between asset the board offices because of the absence of innovation inclusion, and (2) quick urbanization in Malaysia and expanding interest for skyscraper private living way of life because of land shortage, which is increasingly unmistakable in territories with higher thickness of populace. Moreover, classification of living quarters has not been considered (by the asset the board organizations) in metropolitan strong waste administration arranging. This investigation concentrates just on family squander the board in skyscraper private structures. Be that as it may, conceivable outcomes or constraints of execution of the introduced framework in different classes of living quarters are talked about toward the end. The proposed system goes for encouraging the procedure of learning obtaining, 
information the board, and information move in the referenced territory. The results of this examination are by one way or another the present Government's slowed down feasible objectives, which were meant to be accomplished through requirement plan (unsuccessful to date). This investigation attempts to approach the examination issue through an increasingly practical and achievable form, thinking about the present current way of life. This examination, in any case, does not contend over what has (not) been done before, but rather how to utilize the past experience(s) towards the future practical improvement. The proposed system displayed in this paper is joined by a reasonable model, which has been created and imagined dependent on translation of the discoveries of the investigation. In this way, the model can be in fact labeled information perception.

\section{B. 'E-waste Management: Are we ready for it? (Lim Fung Chen, wai yee)}

Electronic waste (e-squander) the executives isn't new in Malaysia. It is constantly identified with the reuse, reuse and lessen of ewaste and these might be the main methodologies of overseeing e-squander today. Essentially, there is no ideal arrangement in e-squander the board. Reuse and reuse just brief exchange the ewaste to different spots and after here and there, the e-squander still arrived on the landfill. Decreasing the utilization of lethal materials is a superior method for overseeing e-squander, yet for time being, it is troublesome and not savvy to supplant and diminish every one of these materials.Creating smartness in people towards waste management (Jagruthi D Atadt, Atheeth S). Openings in taking care of the issues with waste administration individuals all around. The arrangements should be coordinated or focused in an allencompassing sense, at exactly that point, where is it give the issues of all get cleared. It will show arrangement which handles underlying driver on isolation problem which will achieve an extreme change in individuals' standpoint towards overseeing waste, by utilizing a significant test preliminary. Results of which were basically exhibited and approved.

The building of Management System Model tomaintain environmentby clearingsolid waste (Hongtao Shao,Dandan Zhao).To guarantee maintainable advancement in regards to strong waste administration three territories must be guaranteed: natural supportability, prudent maintainability and social acknowledgment. This implies a natural appraisal isn't adequate to put together choices with respect to, why models for assessing ecological results of a strong waste administration framework are choice help apparatuses as framework; can enhance the personal satisfaction for

opposed to choice devices. The outcome from an ecological assessment must be considered alongside budgetary expenses and worthiness in the public arena. The fundamental point of this article consider is to build up an easy to understand and adaptable PC based count demonstrate for ecological appraisal of waste administration frameworks for city strong by clearing waste around. This will help in utilizing life cycle, correlations for various methodologies and distinctive innovations inside a waste treatment technique.

Smart cities and getting old populationhaving solution for waste treating in the Czech Republic (Kristýna Rybová, Charles). European towns urban areas are confronting generous differnce in statistic, financialoccupants. Statisticchiefly connected with populace maturing, for example expanding number and extent of more seasoned individuals in the general public, expanding number of single individual family units and diminishing number of occupants in a few urban areas and locales present new difficulties for savvy urban areas to handle changing state of people in general administrations arrangement. Particularly squander the board is by all accounts influenced by these progressions altogether. Our exploration intended to assess how statistic factors impact the civil strong waste generation and propose a coordinating adjustment arrangement at the nearby dimension. In spite of the fact that outcomes affirmed that statistic factors clarify just few variety civil treating waste over, statistic improvement having truth adjustment strategy ought to be characterize to limit expenses of the adjustment. Not just association of the waste administration benefits in regions, yet additionally the individual strategy of the waste dealing with organizations should remain in the focal point of the intrigue.

\section{BLOCK DIAGRAM}

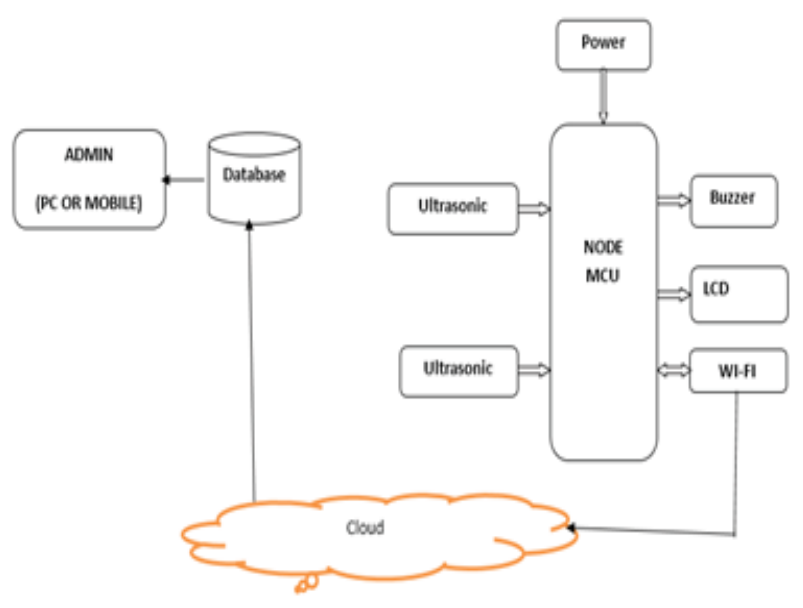

Published By: Blue Eyes Intelligence Engineering 


\section{MOISTURE SENSOR}

This sensor is used to find out the percentage of water present in the soil. As the water content in the soil increase we get a notification and if the limit is reached then we get a buzzer sound which is placed near the dustbin and we get the notification.

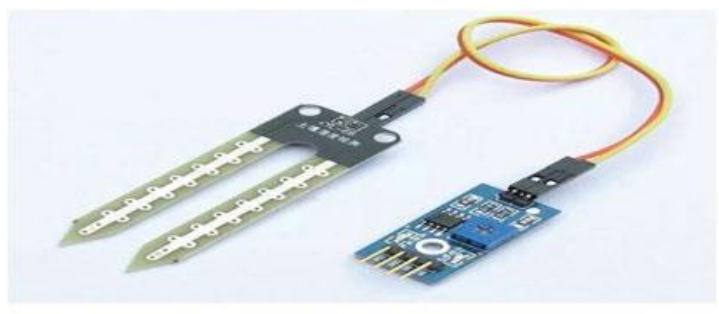

V. ULTROSONIC SENSOR

Ultrasonic sensors are used to get the level of the trash in the bin. The sensors will have the sonic waves emitted bytransducer are meditated by way of an itemand acquired again in the transducer.The sonic waves produced by the transducer are reflected back when it touches an object and these waves are received back by the transducer. After emitting the sound waves, the ultrasonic sensor will change to the receive mode. The time taken between emitting and receiving the ultrasonic waves is directly proportional to the distance of an object from the sensor. Sensors have the on or off option for the output for detecting the movement of the objects as the levels of bin.

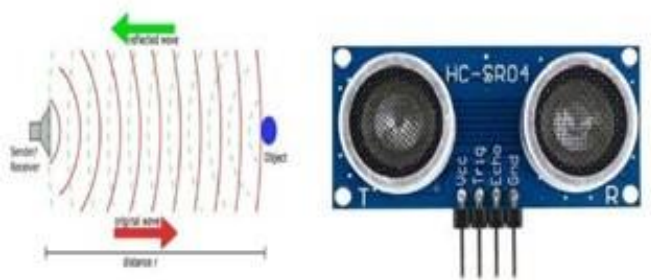

VI. MICROCONTROLLER

Arduino is used as the microcontroller to which the sensors are connected. Arduino is open source platform and is used in developing electronic projects. Arduino has programmable circuit board and some amount of software in it IDE (Integrated Development Environment). This runs on our computer. We write the code manually and upload it to the Arduino board. This Arduino does not need separate hardware for uploading the code as it is built in such a way that the code can be uploaded in it so that the process goes on. We need to use an USB cable to connect between Arduino and the computer. Arduino has the LED light in built. Arduino is developed for creating interactive objects or some new projects. Arduino has ports which can be connected to different sensors as per our choice.

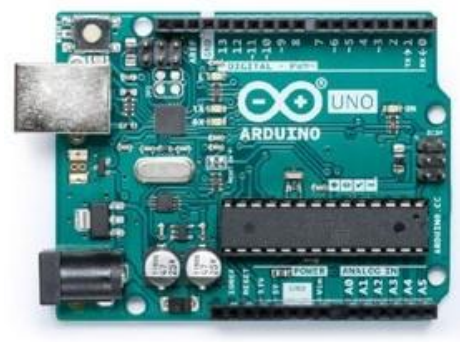

\section{RELATED WORKS}

- Insung Hong has suggested that changing SGS(Smart Garbage Sensor) rather of RFID garbage amassing device facilitates to enhance their energy efficiency as much as $16 \%$ and might reduce the meals waste reduction.Insidethe SGS they've set up SGBs(Smart Garbage Bins) to govern the energy performance of the system.

- Dario Bonino has cautioned that it offers stop-to-quit safety and privacy that is built upon dynamic federation smart city platform.Its advantages is that it has excellent dependability and has resilience on failure of a system over a specific month. It specializes in the gathering of wastages and accomplishment of ontology technique.

- Alvaro Lozano Murciego has advised that to acquire the dustbins which can be been crammed using a truck. The most important benefit is that it reduces the fuel price of the vehicles as opposed to travelling along distance it makes the route moreeasier and less complicated to attain the dustbin the use of route optimization.

- Fachmin Folianto has counseled that it makes use of mesh network.It is used to provide statistics and supply it to the mesh community. Whenever the bins are crammedthey want to be wiped clean. The bin collector offers the route to acquire the boxes.

- Jose M. Gutierrez proposed the useful smartcity and the usage ofan smart waste management.Itmakes use of IoT for sensing the wastage level in the dustbins, techniques the information and sends it to the server for storing and method the records. The manner is done by using the Geographical Information machine.

\section{EXISTING SYSTEM}

- In the current framework trash is gathered by organization by week by week once or by 2 days once. Despite the fact that the junk strinks and floods the trash canister and spread over the streets and contaminates the earth. The smell will be overwhelming and delivers air contamination and spreads malady. The road canines and creatures eats the waste sustenance and speads over the territory and makes filthy condition. 


\section{Smart Waste Management System}

- And furthermore another arrangement of refuse accumulation is present utilizing IEEE 802.11 standared which relies upon the system speed and have issues with exactness of refresh and gathering of waste in time.

\section{PROPOSED SYSTEM}

- The method to overcome the difficulties faced by the dustbins. We use wireless sensors and a microcontroller in this process. Arduino is the microcontroller and the sensors are ultrasonic sensor, mems sensor, moisture sensor. These sensors are connected to the microcontroller. The microcontroller is connected to the computer through the usb cable. We get the values directly through the sensors and based on the data we act on the process to be done. Ultrasonic sensors collect the data as how much the dustbin is filled. Mems sensors is used to get the information if the dustbins is damaged or broken. This sensor is set with a value and if the value is increased the there is a problem with the dustbin. Moisture sensor is used to detect the rain because if the dustbin is filled with water it contaminates and spreads diseases so to avoid that we use this sensor. Each dustbin will have the doors and when there is an information about the weather change we close them when the garbage department comes to collects the waste. This total information provide by each sensor is collected and stored in the server. The department can access the server to login details and can see the data about the dustbin each sensor specifies their results separately and clear to understand

- Manage the loss in various sort of box by utilizing mechanization.

- In this framework the speed of the system does not make a difference similar to an extremely light weight convention which will work with low web speed additionally with a rapid exchange of information.

- Automation for example Machine to Machine correspondence is been finished with the inclusion of any human power.

- Containers send the information to an information the board arrangement of the dimension of waste or last accumulation.

- The proposed device is primarily based at the waste repute of every trash bin in the city.
- The collected statistics is sent over the Internet to the server wherein it's far saved and processed. At here, it's far used for tracking and predicting the repute of every trash bin day by day.

- Moreover, it will likely be utilized for calculating the top of the line rubbish truck routes.

- The prediction status of each bin can be analyzed primarily based at the given schooling information before it takes place.

- Then, it will likely be taken into consideration to update the load of the trash bin as a result, that is the maximum important input parameter of superior garbage truck routes.

\section{A. Case I}

\section{Ultrasonic sensor}

In this case we use ultrasonic sensor to find out the data or how much is the dustbin is filled. The length of the dustbin is known to us. The ultrasonic waves are sent to the dustbin to obtain the data as how much is the dustbin filled. As the dustbin gets filled the length decreases.

\begin{tabular}{|l|l|l|l|l|}
\hline S No & Date & Time & Dustbin 1 & Dustbin 2 \\
\hline 1 & $3-4-19$ & $09: 53: 24$ & 4 & 6 \\
\hline 2 & $3-4-19$ & $09: 58: 45$ & 3 & 4 \\
\hline 3 & $3-4-19$ & $10: 03: 33$ & 2 & 3 \\
\hline 4 & $3-4-19$ & $10: 08: 10$ & 14 & 14 \\
\hline
\end{tabular}

\section{B. Case II}

\section{MEMS Sensor}

This sensor is used to know the position of the dustbin. When the position changes or if it gets damages or disturbed from its position the notification is sent to the server regarding the position.

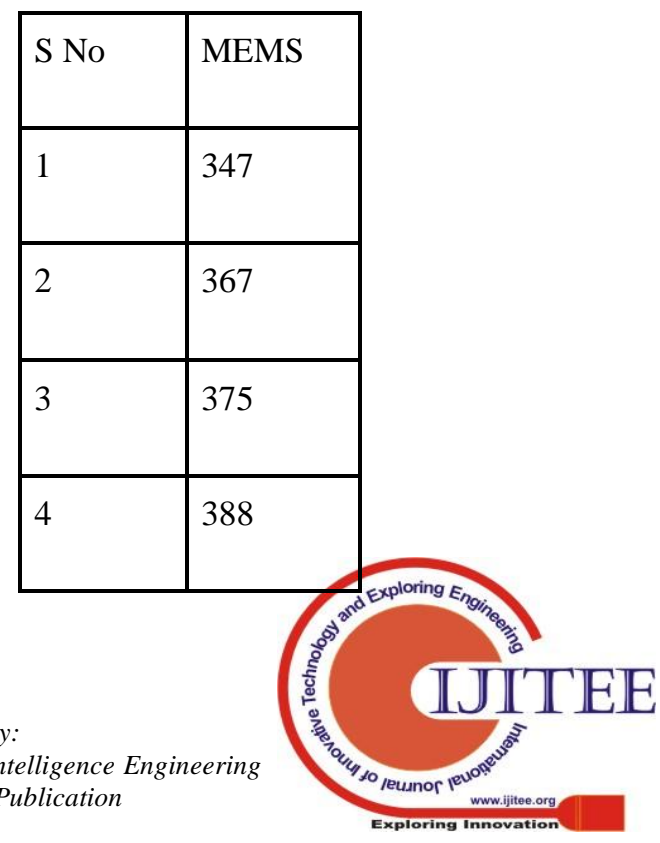




\begin{tabular}{|l|l|}
\hline 5 & 390 \\
\hline 6 & 395 \\
\hline 7 & 401 \\
\hline 8 & 422 \\
\hline 9 & 435 \\
\hline
\end{tabular}

\section{Case III}

\section{Moisture Sensor}

This sensor is used to find out the percentage of water present in the soil. As the water content in the soil increases we get a notification and if is reaches the limit the we get a buzzer sound which is placed near the dustbin and we get the notification.

\begin{tabular}{|c|c|}
\hline S No & Moisture \\
\hline 1 & 2 \\
\hline 2 & 3 \\
\hline 3 & 7 \\
\hline
\end{tabular}

\section{RESULT AND CONCLUSION}

In this we demonstrate the answer for the air borne illnesses caused because of the waste dustbins. Here we use IOT strategy to fathom the issues and the savvy squander theexecutivesframework is our task. We utilize the site page to demonstrate the rate filled in dustbin and furthermore is it strong waste or the fluid waste is additionally known here. The diversion on proposed framework is to get mechanize the strong waste checking procedure and the executives of the general gathering process utilizing IOT. The framework will give the answer for the present system which is little bit expensive and also leads to overflow of trash and gets stinking around it.In this we will give solution for treating the waste utilizing the IoT with the wireless sensor network.

\section{REFERENCES}

1) Volunteer GIS (VGIS) Based Waste Management (S M Labib)

2) C. Republic, "Keen urban communities and maturing populace Implications for waste administration in the Czech Republic," pp. 0- 5, 2016.

3) "The Construction of Management System Model for Environmental Assessment of Solid Waste" (DandanZhao).

4) E-waste Management: Are we prepared for it? (Lim Fung Chen, hai small).
5) "Squander Management utilizing Internet of Things (IoT)"(Himadri Nath Saha, Supratim Auddy, Subrata Pal1, Shubham Kumar, Shivesh Pandey1, Rakhee Singh1, Amrendra) 978-1-5386-2215-5/17/\$31.00 (C)2017 IEEE

6) "Creating intelligence in individuals towards waste administration" (Jagruthi D Atadt, Kishore Kumar) 